\title{
LA DIGNIDAD HUMANA, CONSENSO Y DISENSO VALORATIVOS
}

\author{
Josep R. MONCHO
}

Josep.R.Moncho@uv.es

\section{A) LA DIGNIDAD HUMANA}

\section{Sumario}

1. La dignidad, valor básico fundante

2. Historia del tema en la Antigüedad

3. La dignidad humana en Kant

4. Más allá de Kant

\section{La dignidad humana, valor básico fundante.}

La dignidad humana es un valor que tiene un rango privilegiado en la DUDH.

El preámbulo de ésta y uno de los considerandos de ambos Pactos Internacionales dicen que los valores superiores "tienen por base la dignidad".

Así mismo otro considerando de los Pactos Internacionales dice que "los derechos se desprenden de la dignidad".

Por ambas expresiones se deduce que la dignidad humana es el vértice del conjunto valorativo por una parte y del conjunto normativo por otra.

El rango particular que detenta se puede caracterizar diciendo que es el valor básico fundante. Los demás valores explicitan, contemplan, desarrollan y refuerzan el valor básico.

$\mathrm{Si}$, pues, se construye una ética acorde con los documentos de los derechos humanos, se dirá que la dignidad humana es el fundamento de la ética. Ello con cierto carácter último e irrebasable. Pues rompe la salida de una regresión al infinito que Aristóteles juzga imposible por absurda (EN I, 1,1094 a 20-21).

Y esa parada en la regresión fundamentadora es razonable, porque es decidida por consenso mundial. Es una voluntad universal la voluntad que articula y expone el fundamento.

\section{Historia del tema en la Antigüedad}

Hay un tema recurrente en la teología cristiana que habla del "hombre, rey de la creación". El tema se inspira de la biblia, cuando dice: "llenad la tierra y dominadla; dominad los peces del mar, las aves del cielo y todos los animales que reptan sobre la tierra." (Génesis, 1, 28).

Una idea convergente la presentan los estoicos, al considerar al hombre como fin de todas las criaturas: "como piensan los estoicos, todo lo que crece en la tierra ha sido creado para los hombres, mientras que los hombres han sido creados para los hombres" (Cicerón, De officiis I, 7, 22). Se sugiere así una categoría esencial: la consideración del hombre como fin en sí.

Hay, por otra parte, una frase del Evangelio que es una afirmación potencial y sugestiva de la dignidad humana: "El sábado ha sido hecho para el hombre, y no el hombre para el sábado" (Marcos 2, 27). El sábado representa un precepto eminente de la ley. Luego el dicho evangélico equivale a: "La ley es para el hombre, y no el hombre para la ley". Así entendida la frase, supone al menos virtualmente la idea de dignidad humana, puesto que "para el hombre" lo convierte en fin en sí y absoluto. 
Sin embargo, quien insiste en el fin en sí del hombre, y formula la primera teoría de la dignidad humana, es Kant. Sobre él insistiremos a continuación.

\section{La dignidad humana en Kant}

Kant menciona la dignidad humana en tres ocasiones en la Metaphysik der Sitten: p 305, 317 y 321 (edición de Felix Meiner, Hamburgo 1966). Pasemos en revista dichos pasajes.

P. 305: ..."se entiende una máxima de la limitación de nuestra autoestima por la dignidad de la humanidad en la persona del otro, y por lo tanto el respeto en el sentido práctico (observantia aliis praestanda)". La frase puede entenderse como que el respeto de otro limita la autoestima propia. Aunque se pudiera pensar que el respeto y la autoestima se interlimitan, con todo la limitación de la autoestima es más patente que la hipotética limitación del respeto. Luego parece pensar que la autoestima es susceptible de exceso, mientras que el respeto no lo es, En todo caso el respeto a las personas es una dimensión inevitable de la dignidad humana.

P. 317: "lo cual va contra la auténtica autoestima (sentirse orgullosos de la dignidad humana en su propia persona)" Si el pasaje anterior enlazaba la dignidad con el respeto, este otro pasaje la enlaza con la autoestima, caracterizada como orgullo derivado de la dignidad en uno mismo. De modo que la autoestima es otra dimensión en la que se expresa la dignidad humana.

P. 320: "La humanidad misma es dignidad; Pues el hombre no puede ser utilizado por ningún hombre (ni por otro ni por sí mismo) sólo como medio, sino que debe ser utilizado siempre como fin, y su dignidad (personalidad) estriba precisamente en que él se eleva sobre todos los otros seres del mundo, que no son hombres pero pueden ser utilizados, consiguientemente se eleva sobre todas las cosas. Así, pues, como él no se puede vender a si mismo por ningún precio (sería contradictorio con el deber de autoestima), así tampoco puede obrar contra la autoestima de otros hombres, o sea, está obligado a reconocer prácticamente la dignidad de la humanidad en cada otro hombre; por consiguiente, pesa sobre él un deber, que se refiere al respeto que necesariamente hay que mostrar a cada otro hombre". Este pasaje relaciona la dignidad y autoestima; ya que ambas coinciden en que el hombre no tiene precio. Y presenta el respeto, como favoreciendo la autoestima de otros. Síguese que la autoestima es el primer y más evidente producto de la dignidad, pero que el respeto de otros es un deber, se colige, más exigible.

Por este último pasaje se colige que la nota definitoria de la dignidad estriba en que el hombre, todo hombre, es fin. Las cosas son medios, las personas son fines. Si no media otra consideración, el hombre es fin supremo o fin en sí.

Pero la formulación kantiana contiene una restricción importante: "jederzeit zugleich als Zweck", siempre a la vez como fin. El "a la vez" quiere decir: a la vez medio y fin. Esta formulación es ambigua y posiblemente contradictoria.

Hay los otros dos libros kantianos de moral que contienen cada uno un pasaje paralelo al anteriormente mencionado. Se trata de Grundlegung (Kants Werke IV, Berlin 1911), p.429; y de la Kritik der praktischen Vernunft (Hamburgo 1967, Felix Meiner), p.102.

En la Grundlegung se dice: "El imperativo práctico será, pues, el siguiente: Obra de tal manera que utilices a la humanidad, tanto en tu persona como en la persona de todo otro, siempre a la vez como fin, nunca sólo como medio." Repite el "siempre a la vez como fin, nunca sólo como medio".

En la Kritik se lee: "sólo el hombre, y con él toda criatura racional, es fin en sí mismo. ...éste (el ser racional) utilizarlo nunca sólo como medio, sino a la vez incluso como fin." Repite el "nunca sólo como medio, sino a la vez... como fin". 
Por lo tanto, tres pasajes de tres obras diferentes confirman que el hombre es fin en sí; pero contienen la ambigüedad de considerarlo a la vez como medio y como fin. Conviene empero hacer una caracterización global de la dignidad kantiana, para insertar en ella la temática medio-fin.

Empecemos con el análisis de las notas positivas de la dignidad kantiana.

1.- La persona es afirmada como fin en sí misma (Zweck an sich). Las cosas son medio, las personas racionales son fines. Así se recupera la categoría de causa final que sobresaliera en Aristóteles y, en general, en la antigüedad. Sin embargo, la categoría de fin en Kant es más bien limitadora que dadora de contenido positivo para valores y normas. Con eso sólo hacemos sugerencias para discutir las implicaciones teóricas del fin en sí.

De modo que las cosas son medios, y las personas son fines. Y respecto a Dios, Dios es un fin, pero no anula a las personas humanas como fines. Kant considera "todo ser racional como fin en sí" (Grundlegung p.438, 8-9). Tenemos aquí una incipiente satelitización de Dios: ya no se ve todo "sub specie aeternitatis", sino "sub specie naturae rationalis", o sea, desde el punto de vista de la naturaleza racional en la que comulgamos con Dios. Estamos superando las teleologías tradicionales: la teleología de Aristóteles, con la felicidad como bien supremo y fin último; o la Tomás de Aquino para quien el fin último y bien supremo es Dios. En el fin de Kant pierde el epíteto de último; pero es, aunque no lo diga, único como ente racional; pues todas las cosas son medios.

2.- Voluntad y naturaleza racionales como "situs" de la dignidad. Según veíamos, Kant localiza la dignidad en el ser racional. El ser racional comprende a Dios y a los hombres, no diciéndose nada de los ángeles o espíritus puros. La diferencias y el encumbramiento del fin sobre los medios radica, hemos visto, en la naturaleza racional. Pero ello lleva a la exclusión de la patología o sentimientos del seno de la dignidad. Se puede precisar que la voluntad racional, como sede de la autolegislación es la base de la dignidad.

3.- Todavía queda una nota más esencial, vehiculada por la naturaleza racional. El fín en sí, a través de la voluntad, como ente autolegislador. En todo caso como ser racional es legislador; pues el hombre no es propiedad del soberano: "como ciudadano... que debe ser considerado siempre como miembro colegislador (no sólo como medio, sino también a la vez como fin en sí mismo)" (Metaphysik der Sitten, p.175). Solo un ser auto-legislador es digno; no lo es el súbdito quâ súbdito. Tenemos que el hombre determina y define sus propios fines y metas, de manera consciente. Esto supone la democracia representativa para Kant: "debe dar su libre acuerdo por mediación de sus representantes" (ibídem). Ahora, nosotros hacemos observar que la autolegislación sólo se da de manera plena en la democracia directa. Sin ésta, pensamos, hay merma de la dignidad humana. Quede, pues, patente que sin autolegislación democrática no hay dignidad humana; y diremos que la concepción democrática de Kant no es bastante radical, pese a su admiración por Rousseau. Este punto, más que positivo en la apreciación de Kant, es ambivalente.

A continuación enumeremos aspectos más bien negativos de Kant sobre el contexto de la dignidad humana.

1.- Recordemos que en los tres pasajes paralelos de las tres obras morales de Kant, mencionados anteriormente, se constata idéntica estructura: a) "no sólo medio", b) "sino al mismo tiempo fin". La mínima censura es decir que es una triple ambigüedad; La máxima censura es considerarlo una contradicción. El modo tradicional de salir de una contradicción es haciendo distingos; pero no nos consta que Kant recurra a tal estratagema. Lo que sí podemos atisbar es el motivo de dicha contradicción. El mundo económico, el mercado, y en concreto el mercado del trabajo, suponen que el hombre pueda ser utilizado como medio. Es pues, una concesión al fenómeno burgués del mercado liberal. Por ello, el hombre es utilizado a la vez como fin y como medio, como cosa valiosa y como cosa no valiosa. El asalto a o deterioro de la dignidad se puede rastrear en Kant en tres esferas: a) en el mundo político, b) en el mundo jurídico-penal, c) en el mundo económico. 
1a.- En el mundo político. La Metaphysik der Sitten, p.156, se dice: "Sin ninguna dignidad ahora no puede haber ningún hombre en el estado, pues por lo menos tiene la dignidad de ciudadano." Por la manera de expresarse, la dignidad de ciudadano o súbdito es una dignidad marginal o inferior. La completa dignidad la tiene el legislador (para nosotros el autolegislador o colegislador). El súbdito quâ súbdito sólo tiene una dignidad participada y analógica, podemos decir marginal, dependiente de su obediencia al legislador. Hay un fallo en el ideal democrático de Kant.

1b.- En el mundo jurídico-penal. Según Kant, el delincuente penado "es hecho puro medio del arbitrio de otro", queda reducido a servidumbre (Metaphysik der Sitten, p.156). He aquí una negación abierta de la dignidad y una reducción de los delincuentes al estado cosal. La excepción a la dignidad debería justificarse; pero es una excepción sin justificación posible. Pues nosotros pretendemos que no hay principio superior al de la dignidad, para justificar excepciones a ella. Síguese que el estado y el derecho, coactivos y retributivos, caen bajo las reservas que podemos formular en nombre de la dignidad humana.

1c.- En el campo económico. Los fenómenos económicos, la economía de mercado y, en todo caso, el trabajo son frutos del contrato. (Metaphysik der Sitten, p.157). O sea que Kant bendice el mercantilismo como campo de acción de la libertad. Ahora, una crítica del mercantilismo, inspirada en la "alienación" marxiana, nos revelará discriminaciones vejatorias para la dignidad. En las causas del mercado: el contrato de trabajo no puede ser libre, si la alternativa es morirse de hambre. En los efectos del mercado: el consumo se jerarquiza en estratos, desde la clase monopolizadora a los estratos miserables. Es evidente que el mercado es desigual, que reserva la plena dignidad a una fracción, jerarquizando el resto en estratos superpuestos. Así, ataca el mercado a la propia noción de dignidad, que no admite discriminaciones ni jerarquías.

2.- Kant admite que el hombre es autolegislador. Pero atención: la voluntad legisladora es necesaria: luego no es libre. Esto es un vicio anulador de la autolegislación. Si la autolegislación no es libre, no hay realmente autolegislación, ni autonomía verdadera. Por lo tanto quiebra una nota esencial de la dignidad y del fin en sí.

Según la Metaphysik der Sitten (p. 29-30): "la voluntad - cuando simplemente se refiere a ninguna otra cosa más que a la ley - no puede llamarse ni libre ni no-libre, porque no se refiere a acciones, sino inmediatamente a la legislación para la máxima de las acciones (por lo tanto se refiere a la misma razón práctica); por ende es simplemente necesaria e incapaz de ninguna forzosidad. Sólo el albedrío puede, pues, llamarse libre."

El pasaje merece un breve comentario. Hablando de la voluntad, no es "ni libre ni no-libre"; esto es igual a no necesitada por una fuerza; es "schlecterdings notwendig", "simplemente necesaria" simple y absolutamente. Es una dimensión diferente del "albredrío", siendo éste libre por su parte. Luego la voluntad legisladora, como simplemente necesaria, no es libre, al menos en el sentido corriente de la palabra.

Si la autolegislación es nota esencial del fin en sí y digno, como quiera dicha autolegislación no es libre, no es autolegislación real y auténtica. Negamos que en Kant haya autonomía verdadera. Por lo tanto, quiebra una nota esencial de la dignidad. Nosotros proponemos la autocolegislación por consenso libre que, como tal, es un acto contingente. Es la única manera de introducir la libertad en la autolegislación y en la dignidad del fin en sí.

3.- Exclusión de la patología. - Grundlegung, p. 428, 14-17: "Las propias tendencias, como fuentes de la necesidad /humana/, tienen tan poquito un valor absoluto para que se las desee, que antes bien el deseo universal de cada ser racional ha de ser estar completamente libre de ellas."

Lejos de ser dignas las tendencias, deberían de ser eliminadas. Por patología entenderemos nosotros el conjunto de tendencias, necesidades y sentimientos del ser humano que, en su definición de 'animal racional', pertenecen más bien al aspecto animal o, por lo menos, sensible. 
La raíz de la dignidad está en la racionalidad. Toda inclinación, toda tendencia, toda necesidad 'humana' queda excluida, y se debería desear su exclusión. La "patología", o sea el conjunto de sentimientos, tendencias y necesidades no participan de la naturaleza racional y deben ser excluidos.

Luego Kant prolonga el dualismo platónico y plotiniano. Incluso habla de dos mundos: el "mundo sensible" y el "mundo inteligible". La dignidad reside en éste último, no reside en el hombre sensible. La dignidad afecta al hombre en una dimensión, la racional; la otra dimensión, la patologica o sensible, se ve excluida de la dignidad.

Tenemos la confección de unas categorías metafísicas dualistas que rompen la unidad y sentimiento del hombre. Gran parte del ser humano es objeto de desprecio y repudio. Se predica una razón desencarnada, un hombre mutilado, una razón sin sede humana. Dichas categorías violentan la comprensión de la esfera humana.

\section{Más allá de Kant}

Propondremos superar a Kant, y radicalizar las perspectivas de la dignidad humana, en tres aspectos: en la esfera política, en la esfera económica y en la inclusión de la patología en la dignidad.

a.- Impacto de la dignidad en la esfera política.

La dignidad es referida a un ser legislador, autolegislador, colegislador y autocolegislador.

¿Por qué? Se ha de considerar que el hombre tiene el privilegio de determinar y definir sus metas y fines generales. Y lo hace mediante la ley. O sea, el fin en sí de la dignidad es un fin que se autodefine y autodetermina.

Ahora, si la autocolegislación es posible, entonces le democracia indirecta es insuficiente. Ésta consiste en una delegación imperfecta; supone partidos y facciones; supone la oligarquía en el seno de los partidos; y opera según un principio de la mayoría cercenador.

Mientras que en la democracia directa se cumple el desiderátum de la autocolegislación, y ello, de forma plena. Basta que se centre en la legislación fundamental (leyes constitucionales y leyes penales), dejando lo demás a la reglamentación, sea por parte de una asamblea representativa, sea por parte de un ejecutivo subordinado al legislador.

Un detalle medio-utópico del asunto es que hay que postular para la democracia directa un planteamiento universal y cosmopolita, cosa que ya caracteriza a los valores superiores. Siguiendo y superando la ecuación kantiana entre dignidad y autolegislación, mantendremos que el único régimen que garantice plenamente la dignidad humana, es la democracia directa y universal.

Todo otro régimen es ejercicio de heteronomía, en mayor o menor medida, y en niveles descendentes que suponen que el legislador y los fines de la existencia son externos al común de los individuos humanos. De modo que por una referencia y una definición exógenas se ven mutilados los seres humanos de su dignidad, y se ven reducidos al estado cosal.

b.- Impacto de la dignidad en la esfera económica.

El mercado es una institución medular y definitoriamente no igualitaria, que se subdivide en a) producción, que funciona con unos asalariados reducidos a mercancía y b) consumo, donde el hombre y sus necesidades se ven mediatizados por su poder adquisitivo.

En ambos procesos el hombre se convierte en cosa y pierde su dignidad. Por ejemplo, el hombre-mercancía es por definición hombre-cosa utilizable, teniendo incluso un precio. Nada más contrario a la idea de dignidad.

La aplicación plena del valor de la dignidad humana supondría una transformación radical e incluso la supresión del mercado. Posiblemente hubiéramos de postular la desmonetización de las relaciones humanas y la superación del "homo oeconomicus" o calculador y egoísta. 
Esto sería posible si se estableciese una justicia distributiva eficaz como misión del estado, y que vigilase por la satisfacción pública de las necesidades de la gente, al menos las básicas.

Lo cual sería inevitable caso de verificarse la profecía marxiana de la abolición del trabajo. Ésta necesariamente supondría un colapso del sistema mercantil y puritano, desapareciendo el actual sistema retributivo que, con desigualdades, asegura ahora la subsistencia de la gente (pero con una gran mayoría de marginados). Los fenómenos del maquinismo y la racionalización abogan por la abolición del trabajo; $y$, aunque se conserven los servicios, podrían, en una cultura nueva, optar por salirse del mercado y ser gratuitos.

c.- Inclusión de la patología en la dignidad.

Frente al dualismo kantiano hay que proponer que el hombre, complejo y entero, con inclusión de sentimientos y necesidades, o sea, con inclusión de la "patología", es sede de la dignidad humana.

Un autor lo expresa bien, es Dworkin. Pues divide el monomio kantiano de respeto (“Achtung") en un binomio, compuesto de respeto y consideración. El respeto se dirige a la parte racional o moral del hombre. La consideración se dirige a la parte sintiente del hombre, por la que es capaz de frustración. Por ello dice, hablando del derecho fundamental de la igualdad, que "los individuos tienen derecho a igual consideración y respeto" (Los derecho sen serio, Barcelona 1984, Ariel, P. 272).

Otro camino para integrar la patología estriba en una propuesta de Marx, según lo interpreta Giddens, y que se habrá de atribuir a un momento utópico. Dice Giddens: "En la sociedad socialista, el carácter de la autoridad moral no requerirá la conservación del elemento kantiano de obligación o deber" (El capitalismo y la moderna teoría social, Barcelona 1997, Ediciones Labor S.A., p. 358). Nosotros explicitaremos el tema diciendo que la norma moral y racional causa la constricción o violencia de los sentimientos o patología; y que dicha violencia o constricción de los sentimientos o patología dejará de existir, como marca de la conducta moral, en la sociedad futura e ideal.

Más aún, como quiera que la explotación básica para Marx es económica y social, y recibe el nombre de alienación, podemos perfectamente suponer que la constricción psicológica de los sentiminetos es un reflejo de la explotación social, convirtiéndose así el "yo" en "satélite" del explotador social.

Por lo tanto, postulamos que los sentimientos y necesidades deberan encontrar expresión no forzada ni reprimida, expresión armónica con la norma o razón moral. Y que esto se conseguirá plenamente en la sociedad futura e ideal. Éste es otro rasgo utópico de nuestra concepción de los valores superiores. Y postulamos como ideal la plena armonía entre razón y deseo, o entre razón y sentimientos, o entre éstos y la normal moral. (Cosa que en su tiempo Aristóteles pretendía para la virtud perfecta).

\section{Apéndice: La universalidad de la dignidad humana}

La dignidad humana es universal, al menos implícitamente. Pero hay un principio confirmador de ello. Es el principio de no distinción o no discriminación. (art. $2^{\circ}$ de la DUDH), el cual refuerza y explicita dicha universalidad.

La razón de ello estriba en que toda discriminación resulta en merma y contradicción del ideal: pues se excluyen sujetos de la aplicación del ideal, lo que es una contradicción desgarradora del ideal resultando unos dignos y otros indignos.

Por otra parte, la plena explicación de principios universalizadores, como el de la no discriminación y el de no contradicción, son aplicaciones del principio de la igualdad. Finalmente es el valor de la igualdad que es responsable de la aplicación universalista de la dignidad humana. 


\section{Acta Europeana Systemica $n^{\circ} 4$ \\ B) EL ARGUMENTO PROBATORIO DE LOS DERECHOS HUMANOS Y EL PUNTO DE VISTA METAFÍSICO}

Nuestro artículo sobre "Prolegómenos para una filosofía de los derechos humanos" (Ágora 27:1, 2008, 35-70) hace referencia a un estudio de Alan Gewirth titulado "The Epistemology of Human Rights" (Social Philosophy and Policy 1:2, 1984, 1-24).

Este autor estudia las definiciones-justificaciones de los derechos humanos y deduce de ello doce condiciones del posible argumento probatorio de los derechos humanos.

En esa precisa perspectiva comparamos nuestro argumento con el suyo y vemos sus respectivos méritos. Nuestro argumento también cumple las doce condiciones. Pero vamos a concentrarnos en sus líneas básicas y esenciales.

El punto gravitatorio de nuestro argumento es el consenso universal (según predijeran la mayor parte de los autores de la Escolástica española). Ello comporta la realidad de una razón total y un interés global, superadores de los parcialismos, por coincidencia de la voluntad de todos.

Es tal su contundencia que permite el paso de la norma fáctica al deber ideal.

Luego se siguen: a) el valor básico fundante de la dignidad humana; b) los valores superiores, coadyuvantes: igualdad, fraternidad, libertad, justicia y paz; c) los derechos humanos (privados y sociales).

El punto de vista metafísico constata que, en el posible consenso universal, no existen valores preexistentes en un mundo ideal, anteriores al mundo humano.

El consenso mundial establece un acto creador y generador de valores y normas. Ello nos llevaría a una metafísica de la voluntad normativa, especialmente de la voluntad normativa mundial.

\section{C) NOTA SOBRE LA TESIS DE LA PERSONA COMO FIN EN SÍ}

La tesis kantiana del hombre como fin en sí, se va preparando en la historia; ésta ofrece algunos precedentes, como son ciertas afirmaciones de los estoicos y de Santo Tomás.

Es de notar que la fórmula kantiana tiene una limitación que no viene sugerida en los mencionados precedentes.

Es conocido que la aplicación de la tesis en cuestión oscila entre el hombre y la naturaleza racional como fines. En el caso de los estoicos sólo hablan de los hombres (pero sin negar la racionalidad que les es inherente). En cambio, Santo Tomás y Kant hablan de naturaleza racional. Ésta, según Kant, incluía a Dios y a los hombres, mas los ángeles son pasados en silencio. En Santo Tomás, los ángeles no son a excluir de la naturaleza racional (de la naturaleza intelectiva en este caso). Pero a efectos prácticos se les puede poner entre paréntesis.

\section{Los estoicos según Cicerón}

"Como piensan los estoicos, todo lo que crece en la tierra ha sido creado para los hombres, mientras que los hombres han sido creados para los hombres" (Cicerón: De officiis I, 7, \$22).

Ello supone que los objetos o seres irracionales no son fines; sólo son medios, instrumentos, para los hombres. En una palabra, la humanidad es el fin del universo. Y, dada la pluralidad de personas humanas, éstas son fines entre sí. 
Esto es un precedente clarísimo del "Zweck an sich" de Kant. Es el mismo género de ideas, aunque con una modesta formulación.

\section{Santo Tomás}

Ideas sugeridas en nuestra obra, de próxima aparición: Los fundamentos de la ética tomista: Propuesta de visión actual. Fascículo III: Puesta al día de la teoría tomista de la caridad, p. 152153 (saldrá en Bubok Publishing, S.L.; con posibilidad de bajársela gratis al ordenador propio).

En la Quaestio disputata de caritate (art. 7, solutio) afirma: "Por lo tanto, como sola la naturaleza intelectual sea capaz de alcanzar el bien de la felicidad eterna, sólo la naturaleza intelectual es digna de amor por caridad".

Sostiene que la felicidad eterna, como participación de Dios, es el fin último. Pero ella sólo es accesible a la naturaleza intelectual. Dado que la eterna bienaventuranza es el fundamento de la caridad; síguese que sólo la naturaleza intelectual es digna de caridad, o sea, de ser amada por caridad. Y la caridad es lo que nos relaciona con el fin último.

Estamos a nivel de fines; los seres no racionales no son fines, son medios (o equivalentemente instrumentos).

Un pasaje más pertinente para nuestro tema es la respuesta a la quinta objeción: "hay que decir que en el bien del universo se contiene como principio la naturaleza racional, la cual es capaz de bienaventuranza; a aquélla todas las demás criaturas se ordenan" (sobreentiéndase 'se ordenan a ella como a su fin').

Aunque no se dice taxativamente, la manera corriente de hablar de Santo Tomás presenta el 'orden a' como 'orden al fin'; siendo aquí la naturaleza racional la que encarna al fin.

Tendríamos que la naturaleza racional sería principio y fin del universo, y de todas las demás criaturas.

Esas expresiones vienen a coincidir con la afirmación del fin en sí de Kant. Se ensalza así la supremacía de la humanidad y de la persona humana (a través del circunloquio de la naturaleza racional).

Posteriormente diremos de Kant que afirma el 'fin en sí' conjuntamente con una grave limitación, ambigüedad o contradicción. Pero tal limitación no se da en Santo Tomás.

\section{(3) La fórmula kantiana y sus límites.}

Véase esta idea en el contexto de la 'dignidad humana' en nuestra obra: Teoría de los valores superiores (Campgràfic, Valencia 2003, p. 26-31).

La idea del 'Zweck an sich' es notoria en Kant. Pero desgraciadamente va acompañada de una limitación importante, que suponía una gran ambigüedad, por no decir contradicción: "siempre a la vez como fin, nunca sólo como medio".

La traducción corriente dice "nunca como medio"; pero la traducción correcta dice: "nunca sólo como medio". 
Kant:

Esta afirmación escandalosa, por no decir contradictoria, aparece en tres obras morales de

a) en la Grundlegung zur Metaphysik der Sitten (Kants Werke IV, Berlín 1911, p. 429);

b) en la Metaphysik der Sitten (Felix Meiner, Hamburgo 1966, p. 320);

c) en la Kritik der praktischen Vernunft (Felix Meiner, Hamburgo 1967, p. 109).

La frase en cuestión contiene dos ideas opuestas. Una que el hombre es fin; las cosas son medios, las personas son fines. De no mediar otra consideración, el hombre es fin supremo, o fin en sí.Otra idea: los tres pasajes, de tres obras diferentes, confirman que el hombre es fin en sí; pero contienen la limitación contradictoria de considerarlo 'siempre a la vez' como medio y como fin.

O sea que el fin se metamorfosea y se convierte en medio. Como fin es valor y valor máximo; mas como medio es como las demás cosas, carentes de dignidad.

Esa contradicción kantiana se debe a su apreciación positiva del mercantilismo como área de libertad, Mentalmente no estaba preparado para criticarlo.

Pero el hombre, como fin en sí, reaparece en el "reino de los fines" de manera patente. Además con la connotación del hombre autolegislador.

\section{(4) Conclusión}

Los tres autores mencionados afirman la idea, que culmina en Kant, de la persona como fin en sí.

Pero mientras Kant se sumerge en la ambigüedad, los estoicos y Santo Tomás afirman la idea del fin en sí sin ninguna limitación ni ambigüedad. Y, al parecer con mayor rotundidad que Kant.

Hemos de considerar, sin embargo, una dificultad en la interpretación de Santo Tomás. Si Dios es fin último, el hombre ya no sería fin en sí.

Pero diremos que la nomenclatura de naturaleza racional como principio y fin cubre tres tipos de seres: Dios, los ángeles y los hombres. Por lo tanto, los tres son principio y fin, son fin en sí. Se podría decir que el hombre es fin penúltimo de la creación. Pero mejor sería llamarlo co-fin último, junto con Dios y los ángeles.

Si bien Kant silencia a los ángeles, Santo Tomás los tiene muy presentes. Pero a efectos prácticos cabría ponerlos entre paréntesis. 


\section{D) CONSENSO Y DISENSO NORMATIVOS}

Hoy en día se llama 'derecho de gentes' al derecho positivo internacional universal, adoptado por un consenso universal. Éste engendra una doble estructura normativa: a) los valores superiores o básicos (según la metáfora que se elija: situados en el vértice o en la base y fundamento); enumeraremos: dignidad humana, la libertad en todas sus dimensiones (autonomía moral, libertad política, libertad nacional, libertad individual, libertad sexual, libertad de opinión y expresión, libertad sindical, libertad para contraer nupcias y fundar una familia, libertad de circulación...), y otros valores distintos de la libertad: paz, justicia, igualdad y no discriminación, solidaridad y no coacción; b) los derechos humanos que se basan en los valores básicos precedentes.

Los valores superiores pueden valer e identificarse como axiomas, siendo los derechos humanos concreción o determinación de los valores superiores.

Los derechos humanos suelen clasificarse en derechos civiles, políticos (ambos tipos incluidos en el CIDC\&P), y en derechos económicos, sociales y culturales (incluidos en el CIDESC).

Se han de concebir sin contradicción, de manera coherente. Al ser objeto de consenso universal, ellos mismos son universales.

Pero resulta que hay una serie de libertades incluidas en la declaración. Forzosamente las libertades suponen pluralismo, ruponen tolerancia y, en suma, suponen disenso, tanto sociocultural como a nivel individual o interindividual.

En efecto, aparte la moral universal se dan morales sociales, entre las cuales puede

haber disenso.. A ese propósito haremos dos observaciones que a continuación esquematizaremos.

I esquema: trazamos tres círculos concéntricos: uno exterior, otro intermedio y otro interior. El exterior representa la moral universal, que envuelve los otros dos círculos. El intermedio representa la moral social (simplificadamente nacional), subordinada a la 
universal y sobreponiéndose a la individual, representada ésta por el círculo interior. La disposición de los círculos indica la jerarquía de valores y normas: valores y normas universales preceden a las sociales y con éstas a los individuales.

II esquema: en una sociedad determinada, siendo U1, U2, U3...axiomas universales, E1, E2, E3... axiomas de la sociedad española, F1, F2, F3...axiomas de la sociedad francesa, A1, A2, A3...axiomas de la sociedad alemana, sucedería que la sociedad española tendría los axiomas U1, U2, U3...E1, E2, E3...; la francesa tendría como axiomas $\mathrm{U} 1, \mathrm{U} 2, \mathrm{U} 3 \ldots \mathrm{F} 1, \mathrm{~F} 2, \mathrm{~F} 3 \ldots$; la alemana, U1, U2, U3...A1, A2, A3... Esto supone que los valores universales son compatibles con los nacionales y se pueden pensar sin contradicción. En caso de contradicción los axiomas universales se han de superponer a los nacionales.

Los filósofos clásicos (Aristóteles, Santo Tomás y Kant) defendían la moral universal y única. Mientras que ciertos contemporáneos, sobre todo sociólogos como Durkheim, defienden la pluralidad de morales sociales.

Nuestra conclusión es que moral universal y moral social se complementan si se eliminan las contradicciones. Así podemos pensar en una moral bantú, en una moral china o japonesa, o en una moral inca. Pero esta pluralidad se somete a las normas y valores superiores de rango universal.

Este nuevo derecho de gentes es un derecho positivo internacional; comparte con el derecho de gentes clásico algunas características; por ejemplo responde a un consenso universal, como ya en su tiempo dictaminaban unánimemente los neoescolásticos españoles: así se expresaba Francisco de Vitoria: “es del común consenso de todo el orbe" De iure belli, $\left.n^{\circ} 19\right)$. Expresiones similares presentan Juan de la Peña, Bartolomé de Medina, Pedro de Aragón, Miguel Bartolomé Salón, Gregorio de Valencia, Juan de Sales (citados por Santiago Ramírez, El derecho de gentes, pp.. 144, 141, 160, 168, 170, 171, 172 respectivamente).(Madrid 1955),

Pero con todo eran más monolíticos (a favor de una moral universal tan sólo), de lo que podemos permitirnos hoy.

Por lo tanto, hemos de concluir que moral universal y morales sociales plurales, son compatibles y se complementan, si se eliminan las contradicciones. 
¿Cuáles son las fuentes de los dos tipos de moral? La moral universal se encontrará en los documentos internacionales sobre derechos humanos (DUDH, CIDC\&P, CIDESC). Y suelen estar ratificadas en la mayoría de las constituciones políticas. Las fuentes de las morales sociales se encontrarán en descripciones sociológicas y/o literarias. Su mejor modo de acceso está en la descripción de la cultura de cada país.

Mas, por otra parte, las múltiples libertades reconocidas dejan un gran espacio a las elecciones individuales, declarando lícitas y legales múltiples maneras de comportarse dentro de los derechos.

De ello se sigue que ni todo es objeto de consenso, ni todo es objeto de disenso. Éste supone generosos márgenes de pluralismo y tolerancia. Y así se supera el etnocentrismo que suele afectar a la mayor parte de culturas.

\section{Bibliografía}

RAMÍREZ, S.: El derecho de gentes (Madrid 1955).

TRUYOL I SERRA (Madrid 1994, Tecnos), contiene los principales documentos internacionales ("Declaración Universal de Derechos Humanos", "Convenio Internacional de Derechos Civiles y Políticos", "Convenio Internacional de Derechos Económicos, Sociales y Políticos, etc.). 